\title{
RESTORING FUNCTIONAL AREAS OF CONTINUOUSLY CASTED CYLINDERS
}

doc. Ing. Janette Brezinová, PhD., Ing. Peter Balog, IWE., doc. Ing. Ján Viňáš, PhD., IWE.

Technical University of Košice, Department of Materials Engineering, Mäsiarská 74, 04001 Košice, janette.brezinova@tuke.sk

Keywords: rollers, continual casting, renovation, cladding, surface

\begin{abstract}
the paper proposes the fourth restoration of a roller in continuous casting production lines which can enhance production efficiency and lowers costs. The roller was forged from the material 24CrMoV55 - DIN 17240. The roller has been restored three times and is chosen for further restoration. The roller was restored by submerged arc welding (SAW) where the first layer was made from UP-5-200-CZ wire and the covering layers made from UP-5-45-CZ wire. Quality of the weld deposits were evaluated by measuring the hardness, mixing the weld with basic material and by setting the basic mechanical properties in the critical under-weld deposit area. Structures of the weld deposits were evaluated by light microscopy and their chemical composition was determined by EDX analysis. Based on experiments it can be concluded that rollers can be restored for the fourth time, but the limiting factor is the extent of damage.
\end{abstract}

\section{INTRODUCTION}

In metal production, rollers of continuous casting play an important role. They carry the deformed steel casting and guide the cooled steel strip from the crystallizer. The rollers in continuous casting production lines are exposed to combined wearing. Abrasion is the dominant factor but the adhesive wearing due to cyclic exposure under high temperatures in corrosive conditions (Fig.1) also contributes to their degradation. These factors have a significant influence on the operating life of the rollers in the production line of continuous steel castings $[1,2]$. Several hundred rollers are installed in production lines of continuous steel casting. Roller life can become the limiting factor for efficient long run slab casting operations [3]. With such a high number of rolls, $100 \%$ reliability must be ensured. The amount of the rolls represents a significant part of the expenses in the production operation, that's why the rollers are renovated if possible. Not all of the rollers can be renovated. Selecting the rollers to be renovated requires strict controls which approve or disprove the convenience of that particular roller. The renovations are mostly done when the surface material is absent, where the material with better quality, compared to the original material, is then used [4-6]. Thus the operation life of the renovated component can be longer than the original one. Currently it is possible to renovate rollers three times until they are subsequently excluded from operation. The rollers of continuous castings work in very aggressive conditions. These conditions are caused by the reaction of free hydrogen ions with the slag from the casting powder which have a high content of fluorine. On the rollers surface, corrosive pitting occur and can potentially result in fatigue cracks. If there is a high content of chlorine ions in the cooling water, they become ,the driving force“ for the spreading of the crack's root. Because of these reasons, rollers are exposed to corrosive, adhesive-abrasive conditions [5]. 
The rollers used in production lines for continuous casting are renovated after wearing out. It has been possible to renovate the roll three times so far. Afterwards the roll is excluded. To save material and costs, there has been the effort to apply the fourth cycle of resurfacing whose results are presented in the article.

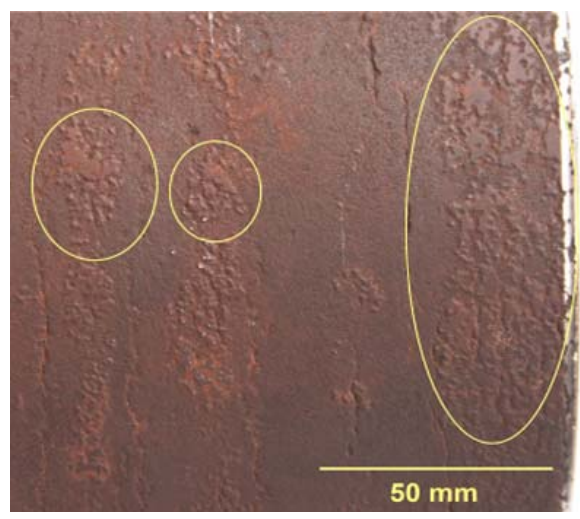

Figure 1: The surface of a worn out roll ø300 mm

\section{EXPERIMENTAL MATERIALS AND METHODS}

An analysis has been carried out on the roller with a diameter of $\varnothing 300 \mathrm{~mm}$ to verify the possibility of resurfacing for the fourth time. Fig. 2 shows the location of the renovated roller. The basic material of the roller was steel labelled 24CrMoV55 - DIN 17240 which has good formability under heat and machinability in the annealed or heat-treated state. It is suitable for engine components strained at higher temperatures. The chemical composition of the roll is shown in tab. 1 and the mechanical properties are shown in tab. 2 [6].

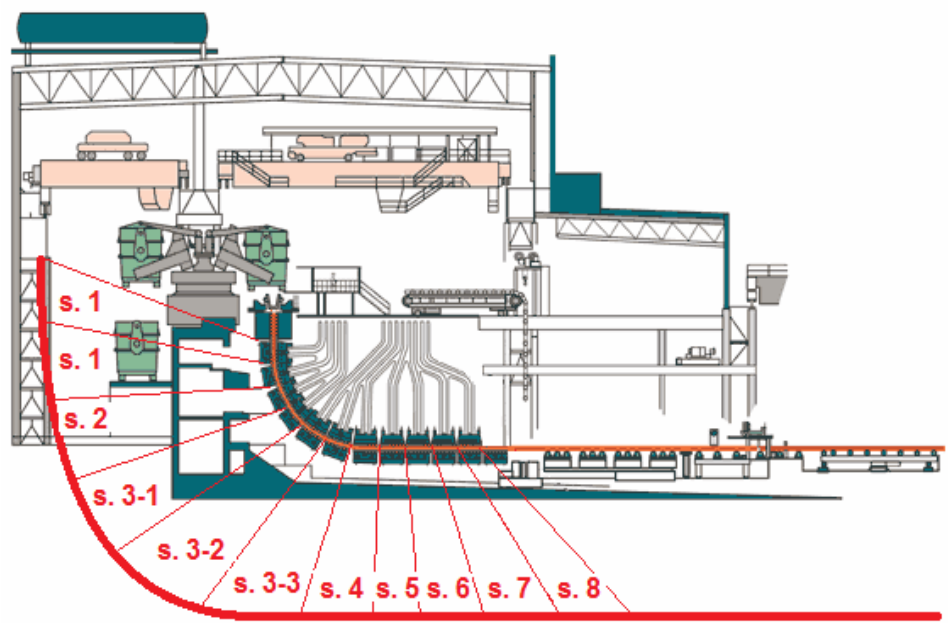

Figure 2: The section arrangement [7] 
Table 1: Chemical composition of steel 24CrMoV55 - DIN 17240 (in wt. \%)

\begin{tabular}{|c|c|c|c|c|c|c|c|c|}
\hline $\mathbf{C}$ & $\mathbf{C r}$ & $\mathbf{M o}$ & $\mathbf{V}$ & $\mathbf{M n}$ & $\mathbf{S i}$ & $\mathbf{P}$ & $\mathbf{S}$ & $\mathbf{F e}$ \\
\hline 0.20 & 1.30 & 0.35 & 0.55 & 0.50 & 0.30 & $\max .0 .035$ & $\max .0 .035$ & bal. \\
\hline
\end{tabular}

Table 2: The mechanical properties of steel 24CrMoV55 - DIN 17240

\begin{tabular}{|c|c|c|c|c|}
\hline $\begin{array}{c}\mathbf{R e} \\
{[\mathbf{M P a}]}\end{array}$ & $\begin{array}{c}\mathbf{R m} \\
{[\mathbf{M P a}]}\end{array}$ & $\begin{array}{c}\mathbf{A 5} \mathbf{~ m i n} \\
{[\%]}\end{array}$ & $\begin{array}{c}\mathbf{K C U} \\
{\left[\mathbf{J . c m}^{-2}\right]}\end{array}$ & HB \\
\hline 540 & $640-670$ & 16 & 45 & $195-223$ \\
\hline
\end{tabular}

The roller assigned for the fourth renovation was first visually tested for the presence of cracks on the body of the roller or in its cooling part. The roll did not have any sign of transcrystal cracks [5]. Consequently the worn-out roll was lathed to a diameter of $14 \mathrm{~mm}$. After turning, it was necessary to visually recheck the surface of the roller again in accordance to STN EN 13018. The ultrasonic method in accordance to STN EN ISO 11666 was used for internal inspection of the roller. It was necessary to preheat the roll up to $200{ }^{\circ} \mathrm{C}$ during which the temperature is continuously controlled even during resurfacing. The range of the surfacing temperatures was from $200{ }^{\circ} \mathrm{C}$ to $380{ }^{\circ} \mathrm{C}$.

In renovating the surface, SAW technology was used in which the cladding was made in three layers $[5,6]$. The first layer was created in a combination with the tubular wire UP-5-200-CZ $\varnothing 2.8 \mathrm{~mm}$ and the addition of F56 with the intention of perfect connection of the basic material with the covering layer. The covering layer was made by combining the wire UP-5-45-CZ ø $3.2 \mathrm{~mm}$ and the addition of F56. The parameters of the surfacing are presented in tab. 3. The chemical composition of the additional materials is displayed in tab. 4. For resurfacing, the addition of F56 (with basicity of 1.4) has been used with the basic chemical composition given in tab. 5 [6].

Table 3: surfacing parameters of the fourth cladding

\begin{tabular}{|c|l|c|c|c|c|c|}
\hline Layer & $\begin{array}{c}\text { Type of the additional } \\
\text { material }\end{array}$ & $\begin{array}{c}\boldsymbol{\emptyset} \text { wire } \\
{[\mathbf{m m}]}\end{array}$ & Flux & $\begin{array}{c}\text { Welding } \\
\text { current - I } \\
{[\mathbf{A}]}\end{array}$ & $\begin{array}{c}\text { Welding } \\
\text { voltage - U } \\
{[\mathbf{V}]}\end{array}$ & $\begin{array}{c}\text { Welding } \\
\text { speed - v } \\
{\left[\mathbf{m . h}^{-1} \mathbf{]}\right.}\end{array}$ \\
\hline First & UP-5-200-CZ & 2.8 & F 56 & 310 & 28 & 25 \\
\hline Covering & UP-5-45-CZ & 3.2 & F 56 & $390-450$ & $30-32$ & 25 \\
\hline
\end{tabular}

Table 4: The basic chemical composition of the additional material (in wt. \%)

\begin{tabular}{|c|c|c|c|c|c|c|c|c|c|c|}
\hline DIN 8555 & C & Mn & Si & Cr & Mo & V & W & Ni & other & Fe \\
\hline UP-5-45-CZ & 0.07 & 0.7 & 0.6 & 13 & 0.7 & - & - & - & $\begin{array}{c}\text { Nb 0.2 } \\
\text { N2 0.12 }\end{array}$ & bal. \\
\hline UP-5-200-CZ & 0.05 & 0.8 & 0.6 & 16.5 & - & - & - & - & - & bal. \\
\hline
\end{tabular}

Table 5: The basic chemical composition with the addition of F56 (in wt. \%)

\begin{tabular}{|c|c|c|c|c|c|c|r|r|r|c|c|}
\hline $\mathbf{S i O}_{\mathbf{2}}$ & $\mathbf{M n O}$ & $\mathbf{F e}_{\mathbf{2}} \mathbf{0}_{\mathbf{3}}$ & $\mathbf{A l}_{\mathbf{2}} \mathbf{0}_{\mathbf{3}}$ & $\mathbf{C a O}$ & $\mathbf{M g O}$ & $\mathbf{C a F}_{\mathbf{2}}$ & $\mathbf{N a}_{\mathbf{2}} \mathbf{O}$ & $\mathbf{K}_{\mathbf{2}} \mathbf{O}$ & $\mathbf{B a F}_{\mathbf{2}}$ & $\mathbf{P}$ & $\mathbf{S}$ \\
\hline $11-16$ & 1 & 1 & $42-48$ & $8-13$ & 1 & $24-30$ & 0.5 & 2.5 & 1 & 0.6 & 0.6 \\
\hline
\end{tabular}

Immediately after surfacing it was necessary to temper the roll. The tempering 
temperature is reached at $540{ }^{\circ} \mathrm{C}$ with a maximum heat speed of $50^{\circ} \mathrm{C} /$ hour and the roller was held at this temperature for about 6 hours. Subsequently the cooling of the roll was set at $40^{\circ} \mathrm{C} /$ hour down to $210{ }^{\circ} \mathrm{C}$ followed by free cooling in air [5,6]. After surfacing and heat treating, the roller was chip machined to a diameter of $\varnothing 300 \mathrm{~h} 10$ for the active part. Final testing of the surface in accordance to STN EN ISO 17637 was carried out as well as the penetration testing according to STN EN ISO 23277 which was assumed to reveal the surface and internal defects. For the detection of inner defects, ultrasonic testing was used according to STN EN ISO 11666. Based on the NDT tests, the roll has been classified as sufficient. After the successful resurfacing of the roller, destructive tests were performed.

For the EDX analysis, samples were taken from the covering layer and observations were performed under a JEOL JSM-35CF microscope. The EDX analysis itself was carried out on the LINK AN10/85S analyser. In cross cuts, the macro and micro structure were evaluated according to STN EN 1321. The examined samples were taken from the basic material (BM), the transition part and the surfacing metal. The samples were etched with the Villela-Bain etcher. The evaluation of microstructure was done with the Olympus TH4-200 light microscope.

The hardness of the cladding, heat-affected zone (HAZ) and BM was performed on the cross cut of the roll according to STN EN ISO 9015-1 using the Vickers' method and the HPO 250 engine loaded at $100 \mathrm{~N}$ at a temperature of $20{ }^{\circ} \mathrm{C}$ where the indenter's operation lasted for 15 seconds. The testing followed the procedures in STN EN ISO 6892-1. During tensile testing the material was removed from the edge of the underclad layer. Testing was carried out with the test engine TIRA, test 2300 , at the temperature $20^{\circ} \mathrm{C}$.

\section{RESULTS}

After the analysis of the cladding quality done by visual, penetration and ultrasonic methods, the cladding of the roller was concluded to be sufficient for reuse. Consequently, destructive testing was carried out on the samples taken from the roller using the above mentioned methods. The chemical composition of the covering layer was identified by the EDX analysis (Tab. 6).

Table 6: Chemical composition of the cladding (in wt. \%)

\begin{tabular}{|c|c|c|c|c|c|c|}
\hline $\mathbf{C}$ & $\mathbf{C r}$ & $\mathbf{M o}$ & $\mathbf{N i}$ & $\mathbf{N b}$ & $\mathbf{N}$ & $\mathbf{F e}$ \\
\hline $0.05-0.07$ & $12.5-13.5$ & $0.7-1.1$ & $3.5-4$ & $\max .0 .2$ & $0.08-0.12$ & bal. \\
\hline
\end{tabular}

The macroscopic and microscopic structure was evaluated in cross cuts of the roller. The macrostructure is in Fig. 3. For better observation of HAZ it was necessary to etch the sample with the Villela-Bain etcher. The width of the HAZ respects the amount of input heat required for the surfacing and duplicates the shape of the surfacing layers. In the macrostructure, defects were not present.

The transition between the basic material

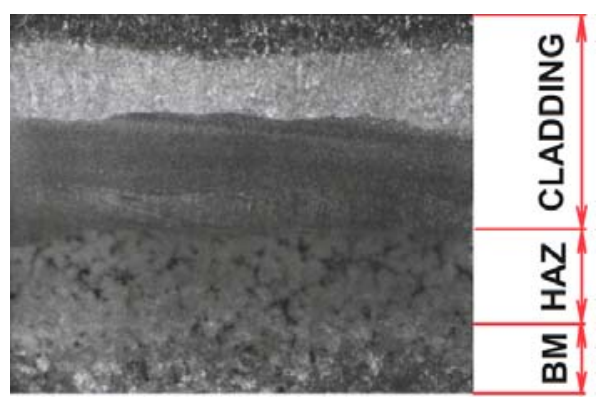

Figure 3: To carry out the already mentioned tests it was necessary to take samples from the roller. 
(Fig. 4) and HAZ was fluent. As a result of the added heat, the transformation from coarse bainitic texture to fine-grained martensite structure occurred. The mixture of the cladding with the HAZ is narrow. The first layer of the clad metal is created by the coarse structure in the transit part. The microstructure of the covering layers can be seen in Fig. 4.

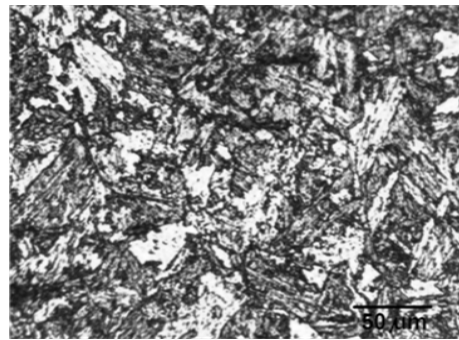

$B M$



HAZ

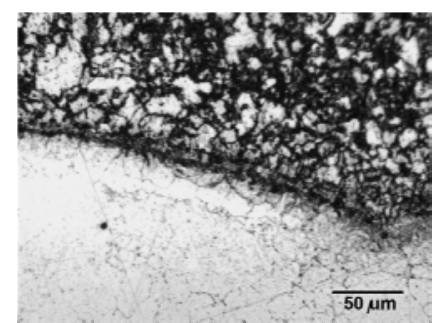

HAZ - cladding

Figure 4 : The microstructure of the basic material, heat-affected zone and heat-affected zone cladding

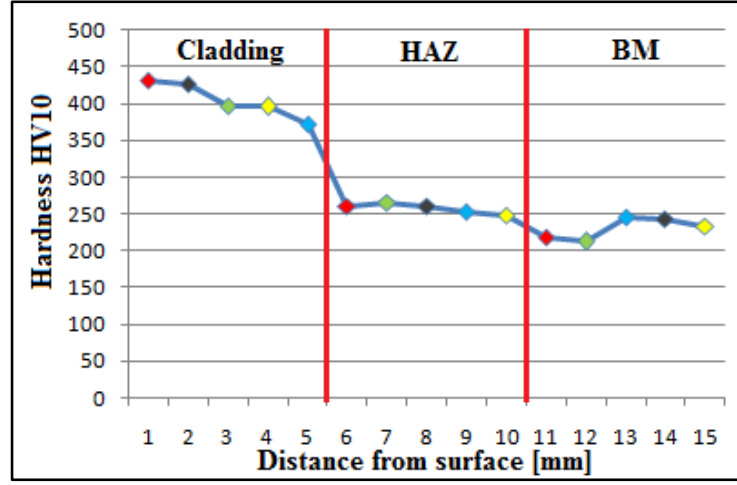

Figure 5: Measured value of hardness

The cladding is made of the martensite structure where carbide part were found. On the cross cut of the roller, the hardness of the cladding has been measured, with the HAZ and BM shown in Fig. 5. The results show that the maximum average hardness was measured in the covering weld layer to the depth of $1 \mathrm{~mm}$ from the surface $435 \mathrm{HV} 10$. With increased penetration, the decline of the hardness was observed. In the HAZ the average measured hardness was 258 HV10. The basic material had an average hardness of 247 HV10.

From the results we can say that the HAZ shows an average value of Rm 939.4 $\mathrm{MPa}$ which represents a $42.3 \%$ increase compared to the heat non-influenced BM. Elongation (A5) has already been increased to the value of $17.3 \%$ compared to BM.

\section{CONCLUSIONS}

The article presents the results from the analysis of the welded layers of the continuous steel casting roller with an average diameter of $ø 300 \mathrm{~mm}$ made from 24CrMoV55 - DIN 17420. The rolls of the continuous casting line are usually renovated a maximum of 3-times before being removed from the line. Due to possible financial savings in metallurgy, the possibility of 
prolonging the operating life of the roller by one more cycle has been tested with the following experiments performed:

- the static tensile testing according to STN EN ISO 6892-1 which confirmed the increase of hardness in the HAZ of the material with average values of $\mathrm{Rm}=939.4 \mathrm{MPa}, \mathrm{Re}=783 \mathrm{MPa}$ and an elongation of $\mathrm{A} 5=17.3 \%$.

- in the welds, the metallographic analysis of the cross cuts has not identified the presence of the internal defects. The structure of the base material of the roller is created by the low temperature martensite.

- the structure of the interlayer and the covering layer was formed by low-carbon martensite. For increased resistance to abrasive wear, the welded metal is alloyed with $\mathrm{Cr}$ and $\mathrm{N}$ whose main role is to strengthen the structure precipitally with carbides and nitrides.

Based on the experimental results we can state that the evaluated roll fulfilled the criteria of renovation quality and could be reused in the continuous casting line.

\section{ACKNOWLEDGEMENTS}

The paper is a contribution from the project „Center for research of control of technical, environmental and human risks for permanent development of production and products in mechanical engineering” (ITMS:26220120060).

\section{REFERENCES}

[1] ČOMAJ, Milan. Problems of surfacing rolls with modern facilities continuous casting. In Zváranie, 1996, Vol. 45, No. 5, p.103

[2] LOOSEN, Baudoin. Surfacing Continuous Casting Rollers Belgium. In: Svetsaren, 1995, No. 2, p. 1-3

[3] SANZ, Alejandro. New coatings for continuous casting rolls. In: Surface and Coatings Technology, 2004, Vol. 177-178, p. 1-11

[4] SCHREWE, Hand. Continuous Casting of Steel: Fundamental Principles and Practice. Stahl und Eisen. Verlag Dusseldorf, 1989, ISBN 3-514-00389-0 p. 196

[5] BREZINOVÁ Janette, BALOG Peter, VIŇÁŠ Ján. Possible exploitation of SAW technology in renovation of continuous casting rollers, In: Zváranie, 2012, Vol. 61, No. 7-8 (2012), p. 166-170. - ISSN 0044-5525

[6] BALOG Peter. Renovation of rollers of continual casting line fourth cladding, Diploma work. Košice: Technical University. Faculty of Mechanical Engineering. Department of Technologies and Materials, $2011.72 \mathrm{p}$.

[7] http://www.salzgitter-flachstahl.de 